\title{
An effect of spinal and ankle-foot orthoses on gait of spastic diplegic child: A case report
}

\author{
Jurgita Ziziene $^{\mathrm{a}, *}$, Kristina Daunoraviciene ${ }^{\mathrm{a}}$, Giedre Juskeniene ${ }^{\mathrm{b}}$ and Jolanta Pauk ${ }^{\mathrm{c}}$ \\ ${ }^{a}$ Department of Biomechanical Engineering, Faculty of Mechanics, Vilnius Gediminas Technical \\ University, Vilnius, Lithuania \\ ${ }^{\mathrm{b}}$ Health Science Institute, Department of Rehabilitation, Physical and Sports Medicine, Faculty of \\ Medicine, Vilnius University, Vilnius, Lithuania \\ ${ }^{\mathrm{c}}$ Biomedical Engineering Institute, Bialystok University of Technology, Bialystok, Poland
}

Received 16 August 2021

Accepted 21 September 2021

\begin{abstract}
.
BACKGROUND: In children with spastic cerebral palsy (CP), the most common motor dysfunction is pathological gait. OBJECTIVE: To evaluate the effectiveness of measures for an individual $\mathrm{CP}$ case.

METHODS: The case of one spastic diplegia child has been analyzed. Both lower extremities and spine were examined under three gait conditions: 1) barefoot, 2) with ankle-foot orthoses (AFOs) and thoracolumbosacral spinal orthosis (TLSO), and 3) with TLSO only. Spatiotemporal gait and kinematic parameters of the pelvic, hip, knee, ankle joints, and spine were obtained using Vicon Plug-in-Gait model. The difference $(\Delta)$ between the measured values and normative ranges was calculated to determine the efficiency of the orthoses.

RESULTS: Significant differences were found in kinematic and spatiotemporal parameters comparing results between conditions and body sides. The effectiveness of the measures was confirmed by the smallest $\Delta$ values in the double and single support time with the AFOs/TLSO and in the stride and stance time with TLSO.

CONCLUSIONS: Based on the study results, the best stability of the spine, ankle plantarflexion, and knee hyperextension is achieved with the AFOs/TLSO; therefore, this combination of measures was considered the most effective. However, not only quantitative parameters should be taken into account, but also the child's willingness and comfort.
\end{abstract}

Keywords: Cerebral palsy, spastic diplegia, children's gait, kinematics, ankle-foot orthosis, thoracolumbar spinal orthosis, effectiveness

\section{Introduction}

In children with spastic cerebral palsy (CP), among other disorders, the most common motor dysfunction is pathological gait, which in the literature is divided into pathological gait patterns according to the form of CP [1-3]. Pathological gait is characterized by: walking on the tips of the toes due to spasms of

\footnotetext{
${ }^{*}$ Corresponding author: Jurgita Ziziene, Department of Biomechanical Engineering, Faculty of Mechanics, Vilnius Gediminas Technical University, Vilnius, Lithuania. Tel.: +370 68380097; E-mail: jurgita.ziziene@ vilniustech.lt.
} 
the calf muscles and tendons, asymmetry, slower pace, lack of stability, i.e. atypical joint movements, impaired muscle control, changes in time-distance parameters, etc. [4-6]. Motor dysfunction may be more noticeable or problematic at different periods in persons with CP [7]. Spastic CP gait compared to normal pediatric gait [8] are characterized by increased amplitudes of joints in these movements: ankle dorsiflexion (dynamic equinus) or ankle plantarflexion during the stance phase of gait; knee flexion or hyperextension; hip flexion, adduction, and internal rotation; and anterior pelvic tilt during the stance phase of gait [9]. The following deviations of the spatiotemporal parameters from the norms also occur [10-12]: walking velocity, cadence, stride length, step length, stance phase, and single support phase decrease; step width, double support, and swing phases increase $[13,14]$. Various therapeutic measures, including orthoses, are used to improve the spatiotemporal, kinematic, and kinetic parameters of CP children's gait, as well as their independence [15-17]. Our study focused on the spastic diplegic CP gait.

AFOs are commonly used for spastic diplegic CP gait, which may have different construction, materials, stiffness, or ankle joint control. Commonly used are solid, hinged or posterior leaf spring AFO's [18]. Solid AFO (sAFO) is regularly used to correct dynamic equinus, hinged AFO (hAFO) is used to correct equinus deformity, improve postural control and gait parameters, etc., posterior leaf spring (PLS) AFO facilitates ankle dorsiflexion by limiting plantarflexion [19]. Researchers are extensively studying the effectiveness of AFO orthoses and their influence on CP gait parameters using optical cameras systems, inertial sensors, force plates, and other techniques. It has already been found that for most spastic diplegic children, sAFO and PLS are best suited to restrict ankle movements [19]. However, this cannot be stated unequivocally, because it is very important to properly assess the child's motor functions and be able to choose an individual orthosis, which is highly dependent on the experience of the specialist [20]. Therefore, before choosing the orthopedic measures it is recommended to perform a comprehensive gait analysis where collected parameters allow to adapt individual orthosis [21]. Also, the whole set of applied therapeutic measures can have a positive effect on gait parameters [22]. In addition, children with CP tend to have other accompanied disorders that affect gait, such as scoliosis [23-25]. It was determined, that the trunk position is correlated with the excessive knee flexion severity and ankle joint kinematic in CP children with crouch gait patterns [24]. There is also a relationship between standing balance, which is affected by the position of the spine, and kinematic gait parameters [26].

The main goal of our study is to investigate individual gait parameters of spastic diplegic CP child under different conditions and to determine the influence and effectiveness of the orthoses used. To achieve this goal, the following tasks were set: 1) to perform experimental studies of a child's gait while walking barefoot, together with AFOs and TLSO, and with TLSO only; 2) calculate gait spatiotemporal and kinematic parameters based on the Vicon Plug-in-Gait model; 3) perform comparative analysis and evaluate the effectiveness of the orthoses.

\section{Methods}

\subsection{Case description}

The subject of this study was a $117.5 \mathrm{~cm}$-tall 6-years- 8 -months-old male with a body mass of $21 \mathrm{~kg}$. From birth, he was diagnosed with congenital heart defects and heart failure. The boy was also observed due to developmental delay. Any genetic pathology is not found yet. Regular rehabilitation courses were provided from the early months up to now as well as pharmacological medications. At 2 years of age, he got a diagnosis of spastic diplegic cerebral palsy. Finally, after several surgical interventions at age of 


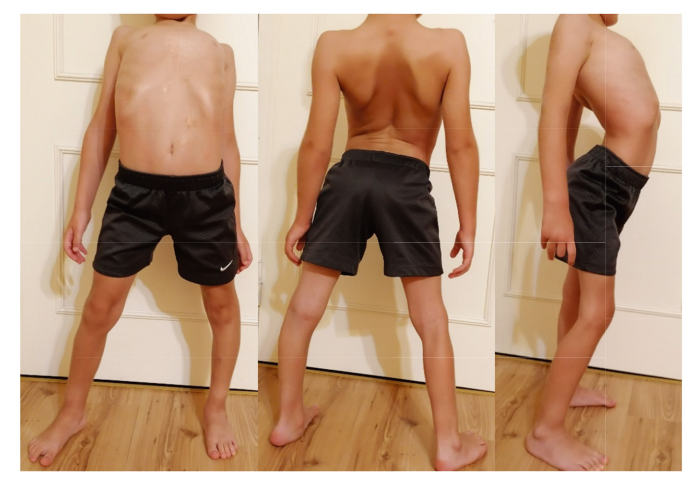

Fig. 1. Subject (parental permission received).

2 years and 9 months, orthotopic heart transplantation and aortic arch reconstruction were performed. The subject began walking with assistance short distances at 4 years of age. At 5 years of age diagnosed epilepsy. At the same age after the spinal radiograph was performed, thoracolumbar scoliosis $\left(\mathrm{Cobb} 36^{\circ}\right)$ and lumbar lordosis were confirmed. From that time boy is wearing a spinal brace (TLSO) for 23 hours a day. Because of impaired gait and balance, the boy was equipped with an individually improved AFO for both legs. He continues with intensive rehabilitation courses (average duration 24 days) 2-3 times per year (including physiotherapy, occupational and speech therapies, etc.). At 6 years of age, he has a Level III classification System on the Gross Motor Function Classification System for Cerebral Palsy, indicating an ability to ambulate with the aid of an assistive device. 6MWT (six minutes' walk test) performed using only TLSO showed better results versus scores using both TLSO and AFO's.

\subsection{Description of orthoses}

In this study, the AFOs and TLSO were custom-made according to the patient's condition and his anthropometric parameters (see Fig. 2).

The solid AFOs used in this study were made from $3 \mathrm{~mm}$ thermoplastic - polyethylene. A perforated Sportolon (Ottobock) has been glued to the foot area, which prevents the foot from skiing and sweating, and performs a cushioning function. Pedilen (Ottobock) glued to the ankle area. The uniqueness of these orthotics is the stabilization of the knee joints, to prevent them from varus deformities. The number of straps was chosen based on the stability of the leg in the orthosis.

The rigid TLSO orthosis was made from $3 \mathrm{~mm}$ 3D-Lite thermoplastic with additional attachments in areas with higher loads due to high deformity of the spinal cord deformity.

\subsection{Experimental protocol}

The experimental protocol was approved by the regional ethical review board (No. 2020/9-1256-738). One case was singled out from all and analyzed separately. Parental consent and child assent were obtained before participation in the study.

In this study, gait was measured using an 8-cameras Vicon recording system (Oxford Metrics Group, Oxford, UK) at $100 \mathrm{~Hz}$. A single force plate Bertec (Bertec, USA, load capacity $5000 \mathrm{~N}$ ) at $1000 \mathrm{~Hz}$ sampling was used only to determine gait events. Before starting the measurement, thirty-nine Vicon reflective markers were then fixed on the subject's body comprising the full-body Plug-in-Gait marker set (for all three conditions) and anthropometric data were measured. In gait measurement with orthoses, 


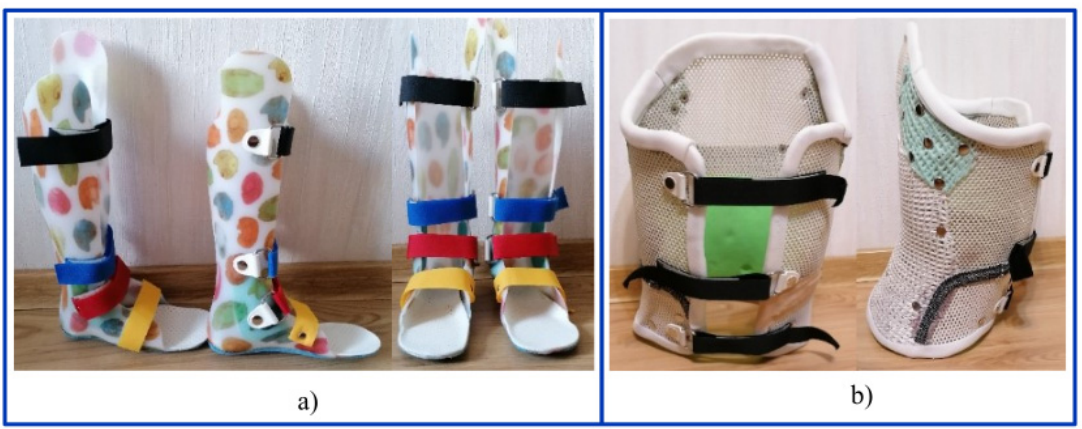

Fig. 2. AFOs (a) and TLSO (b) used in this study.

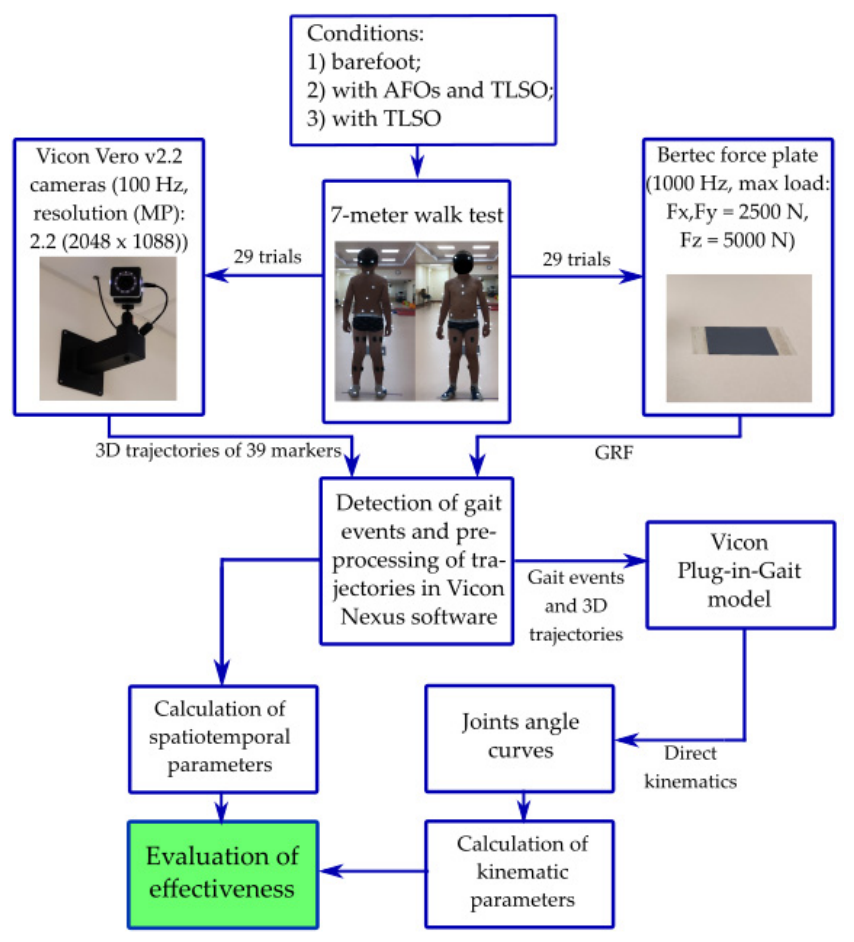

Fig. 3. Flowchart of the study.

markers that could not be applied to the skin due to the orthosis were affixed to the surface of the orthoses themselves. The flowchart in the Fig. 3 presents all steps of the study.

The subject walked 7 meters at a comfortable speed under three different conditions: 1) barefoot; 2) with AFOs on both legs and TLSO; 3) with TLSO. Measurements of each different condition were performed on 3 different days in a row to avoid the fatigue factor.

A total of 29 trials and 332 strides were measured for both legs, of which 10 trials and 88 strides barefoot, 7 trials and 98 strides with AFOs and TLSO and 12 trials and 146 strides with TLSO. For each measurement, gait events were determined, i.e., heel contact and toe-off, and gait spatiotemporal parameters are calculated based on the direct kinematics Plug-in-Gait model in Vicon software. The obtained results were exported and later processed in the Matlab software package. 

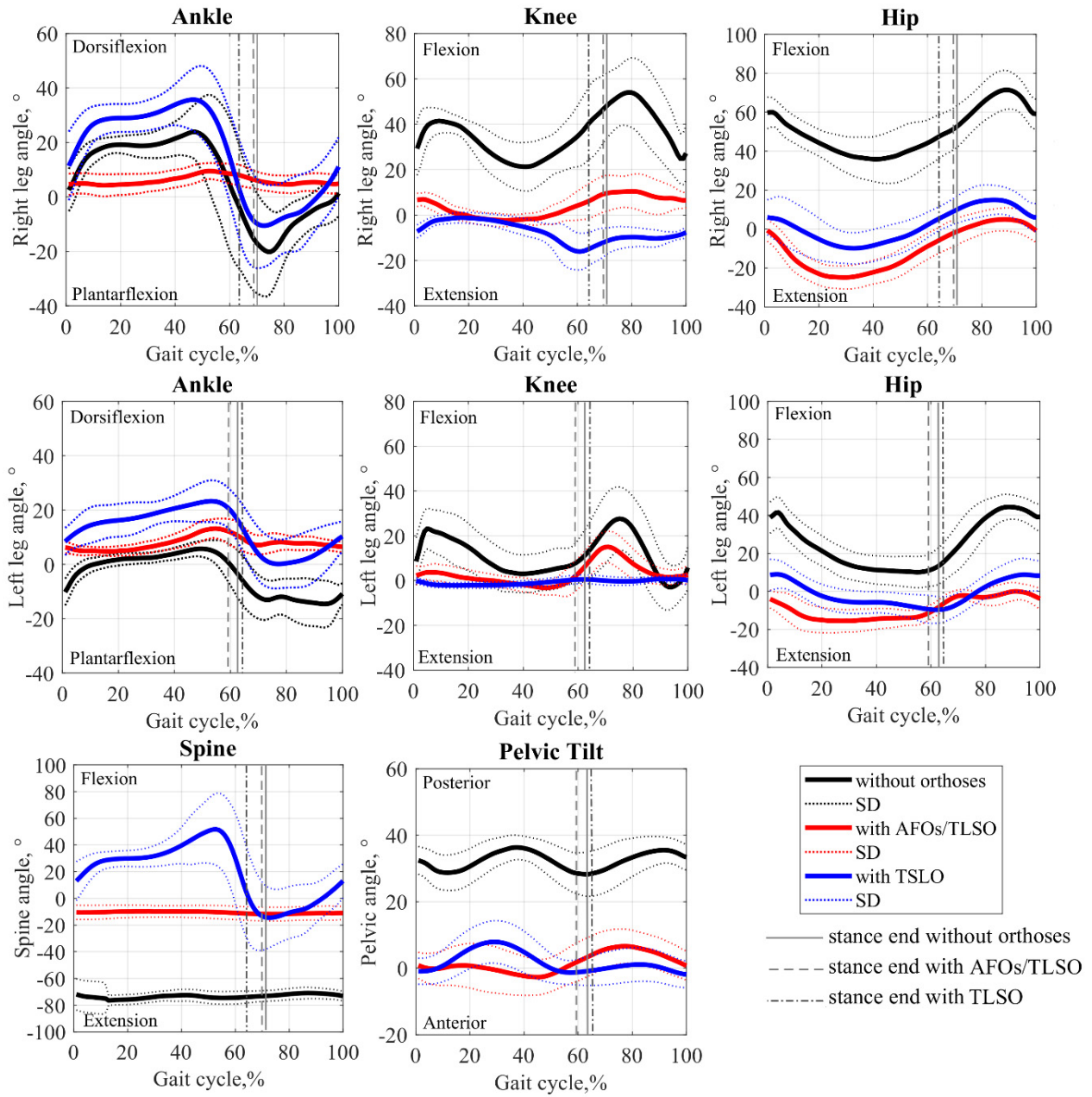

Fig. 4. Curves of joints amplitudes in the sagittal plane under different conditions.

\subsection{Data processing sequence}

Initially, the averages of the spatiotemporal and kinematic parameters of each of the 29 measurements with standard deviation for each of the conditions were calculated. The joint angle curves obtained during the experimental measurements were cut into strides according to the determined gait events and normalized in the gait cycle from heel contact to heel contact. Hip, knee, spine flexion/extension (F/E), ankle dorsiflexion/plantarflexion (D/P), and pelvic tilt movements were assessed in the sagittal plane. The extreme values of each joint movement were found and the range of motion (ROM) as the difference between these values was calculated.

The following spatiotemporal parameters were analyzed: cadence, walking speed, stride time, step time, stride length, step length, step width, and the time of double support, single support and stance.

Finally, the difference $(\Delta)$ between the measured mean values and normative values $[8,10,12,24,28]$ is calculated to determine the efficiency of used orthoses. A negative value of $\Delta$ means that the value of the measured CP gait condition is less than the norm, and a positive value means that it is higher. 
Table 1

Extremum values of joints amplitudes in sagittal plane $(n=332)$

\begin{tabular}{|c|c|c|c|c|c|}
\hline Parameters & $\begin{array}{l}\text { Body } \\
\text { side }\end{array}$ & $\begin{array}{l}\text { Normative } \\
\text { values }\end{array}$ & $\begin{array}{c}\text { Without orthoses } \\
n=88\end{array}$ & $\begin{array}{c}\text { With AFOs/TLSO orthoses } \\
n=98\end{array}$ & $\begin{array}{c}\text { With TLSO orthosis } \\
n=146\end{array}$ \\
\hline Ankle dorsiflexion, ${ }^{\circ}$ & Right & $37.03^{[8]}$ & $30.7 \pm 4.3^{*+}$ & $12.2 \pm 2.8^{+x}$ & $40.2 \pm \mathbf{5 . 8}^{* x}$ \\
\hline & Left & & $7.7 \pm 2.5^{*+}$ & $16.6 \pm 3^{+6} 6^{+x}$ & $25.5 \pm 4.9^{* x}$ \\
\hline$\Delta, \stackrel{\circ}{\circ}$ & $\begin{array}{l}\text { Left } \\
\text { Right }\end{array}$ & - & $\begin{array}{l}-6.33 \\
-29.33\end{array}$ & $\begin{array}{l}-24.83 \\
-20.43\end{array}$ & $\begin{array}{l}3.17 \\
-11.53\end{array}$ \\
\hline Ankle plantarflexion, ${ }^{\circ}$ & Right & $-8.07^{[8]}$ & $\begin{array}{l}-29.4 \pm 13.3^{*+} \\
-20.7+6.7^{*+}\end{array}$ & $\begin{array}{l}1.8 \pm 3.2^{+x} \\
3.1+1.3^{+x}\end{array}$ & $-20.4 \pm 15.7^{* x}$ \\
\hline$\Delta,{ }^{\circ}$ & $\begin{array}{l}\text { Left } \\
\text { Right }\end{array}$ & - & $\begin{array}{l}-20.7 \pm 0.7 \\
21.33 \\
12.63\end{array}$ & $\begin{array}{l}\mathbf{3 . 1} \pm \mathbf{1 . 3} \\
9.87 \\
11.17\end{array}$ & $\begin{array}{l}-\mathbf{5 . 2} \pm \mathbf{8 . 4} \\
28.47 \\
-2.87\end{array}$ \\
\hline Knee flexion, ${ }^{\circ}$ & $\begin{array}{l}\text { Right } \\
\text { Left }\end{array}$ & $66.02^{[8]}$ & $\begin{array}{l}\text { 66.3 } \pm \text { 7.5 }^{*+} \\
37.3 \pm \text { 8.6 }^{*+}\end{array}$ & $\begin{array}{l}17.1 \pm 6.4^{+x} \\
19.3 \pm 6.3^{+x}\end{array}$ & $\begin{array}{l}38.6 \pm 8.3^{* x} \\
36.9 \pm 7.1^{* x}\end{array}$ \\
\hline$\Delta,{ }^{\circ}$ & $\begin{array}{l}\text { Left } \\
\text { Right }\end{array}$ & - & $\begin{array}{l}0.28 \\
-28.72\end{array}$ & $\begin{array}{l}-48.92 \\
-46.72\end{array}$ & $\begin{array}{l}-27.42 \\
-29.12\end{array}$ \\
\hline Knee extension, ${ }^{\circ}$ & $\begin{array}{l}\text { Right } \\
\text { Left }\end{array}$ & $\mathrm{NA}^{[8]}$ & $\begin{array}{l}12.9 \pm \mathbf{8 . 8}^{*+} \\
-\mathbf{9 . 2} \pm \mathbf{7 . 1}^{*+}\end{array}$ & $\begin{array}{l}-3.9 \pm 2.5^{+x} \\
-4.9 \pm 2.9^{+x}\end{array}$ & $\begin{array}{l}6.9 \pm 6.8^{* x} \\
7.9 \pm 6.7^{* x}\end{array}$ \\
\hline$\Delta,{ }^{\circ}$ & & & $\begin{array}{l}12.9 \\
-9.2\end{array}$ & $\begin{array}{l}-3.9 \\
-4.9\end{array}$ & $\begin{array}{l}6.9 \\
7.9\end{array}$ \\
\hline Hip flexion, ${ }^{\circ}$ & $\begin{array}{l}\text { Right } \\
\text { Left }\end{array}$ & $40.98^{[8]}$ & $\begin{array}{l}\mathbf{7 3 . 8} \pm \mathbf{9 . 4}^{*+} \\
\mathbf{4 9 . 4} \pm \mathbf{5 . 5}^{*+}\end{array}$ & $\begin{array}{l}\mathbf{6 . 9} \pm \mathbf{6 . 2}^{+x} \\
3.5 \pm \mathbf{4 . 4}^{+x}\end{array}$ & $\begin{array}{l}19.2 \pm 7.6^{* x} \\
14.4 \pm 6.9^{* x}\end{array}$ \\
\hline$\Delta,{ }^{\circ}$ & $\begin{array}{l}\text { Left } \\
\text { Right }\end{array}$ & - & $\begin{array}{l}32.82 \\
8.42\end{array}$ & $\begin{array}{l}-34.08 \\
-37.48\end{array}$ & $\begin{array}{l}-21.78 \\
-26.58\end{array}$ \\
\hline Hip extension, ${ }^{\circ}$ & $\begin{array}{l}\text { Right } \\
\text { Left }\end{array}$ & $-9.93^{[8]}$ & $\begin{array}{l}31.7 \pm \mathbf{7 . 9}^{*+} \\
\mathbf{6 . 7} \pm \mathbf{6 . 6}^{*+}\end{array}$ & $\begin{array}{l}-\mathbf{2 6 . 2} \pm \mathbf{5 . 2}^{+x} \\
\mathbf{- 1 8 . 7} \pm \mathbf{4 . 2}^{+x}\end{array}$ & $\begin{array}{l}-11.4 \pm 7.8^{* x} \\
-12.7 \pm 5.5^{* x}\end{array}$ \\
\hline$\Delta,{ }^{\circ}$ & $\begin{array}{l}\text { Left } \\
\text { Right }\end{array}$ & & $\begin{array}{l}41.63 \\
16.63\end{array}$ & $\begin{array}{l}16.27 \\
8.87\end{array}$ & $\begin{array}{l}1.47 \\
2.77\end{array}$ \\
\hline Spine flexion, ${ }^{\circ}$ & - & $2.3^{[28]}$ & $-66.7 \pm 11.2^{*+}$ & $-7.8 \pm 4.7^{+x}$ & $61.9 \pm 24.2^{* x}$ \\
\hline$\Delta$, & - & - & 69.0 & 10.1 & 59.6 \\
\hline $\begin{array}{l}\text { Spine extension, }{ }^{\circ} \\
\Delta,{ }^{\circ}\end{array}$ & - & $\begin{array}{l}0.7^{[28]} \\
-\end{array}$ & $\begin{array}{l}-79.0 \pm 3.1^{*+} \\
80.6\end{array}$ & $\begin{array}{l}-13.3 \pm 5.1^{+x} \\
14.0\end{array}$ & $\begin{array}{l}-29.1 \pm 22.4^{* x} \\
29.8\end{array}$ \\
\hline $\begin{array}{l}\text { Pelvic tilt posterior, } \\
\Delta,{ }^{\circ}\end{array}$ & - & $\begin{array}{l}\mathrm{NA}^{[8]} \\
-\end{array}$ & $\begin{array}{l}39.0 \pm 3.1^{*+} \\
39.0\end{array}$ & $\begin{array}{l}8.9 \pm 4.9^{+} \\
8.9\end{array}$ & $\begin{array}{l}9.8 \pm 5.2^{*} \\
9.8\end{array}$ \\
\hline $\begin{array}{l}\text { Pelvic tilt anterior, } \\
\Delta,{ }^{\circ}\end{array}$ & $\begin{array}{l}- \\
-\end{array}$ & $\begin{array}{l}14.37^{[8]} \\
-\end{array}$ & $\begin{array}{l}23.9 \pm 5.9^{*+} \\
9.53\end{array}$ & $\begin{array}{l}-5.5 \pm 4.2^{+} \\
19.87\end{array}$ & $\begin{array}{l}-4.7 \pm 3.3^{*} \\
19.07\end{array}$ \\
\hline
\end{tabular}

Data presented as mean \pm SD. ${ }^{*}-$ a significant difference $(p<0.05)$ between without orthoses and with TLSO orthosis. ${ }^{+}-$a significant difference $(p<0.05)$ between without orthoses and with AFOs/TLSO orthoses. ${ }^{x}-$ a significant difference $(p<$ $0.05)$ between with TLSO orthosis and with AFOs/TLSO orthoses. Bold indicates a significant difference $(p<0.05)$ between right vs left. NA - not applicable. Norms have been taken from available scientific papers and sources are cited for each.

\subsection{Statistical analysis}

The Lilliefors Normality Test was used to check the normality of the data [27], and normally distributed data were presented as the mean \pm standard deviation (SD). Additionally, interquartile range (IQR) as $25^{\text {th }}$ and $75^{\text {th }}$ percentiles was calculated for spatiotemporal parameters. A parametric two-sample paired $t$-test $(p<0.05)$ was used for comparing normally distributed data: between spatiotemporal, extremums and ROM values of all three conditions and between right vs left. Statistical analysis was performed using the MatlabR2019b software (MathWorks Inc., USA).

\section{Results}

Figure 4 and Table 1 show the kinematic parameters under three gait conditions. The amplitudes of 


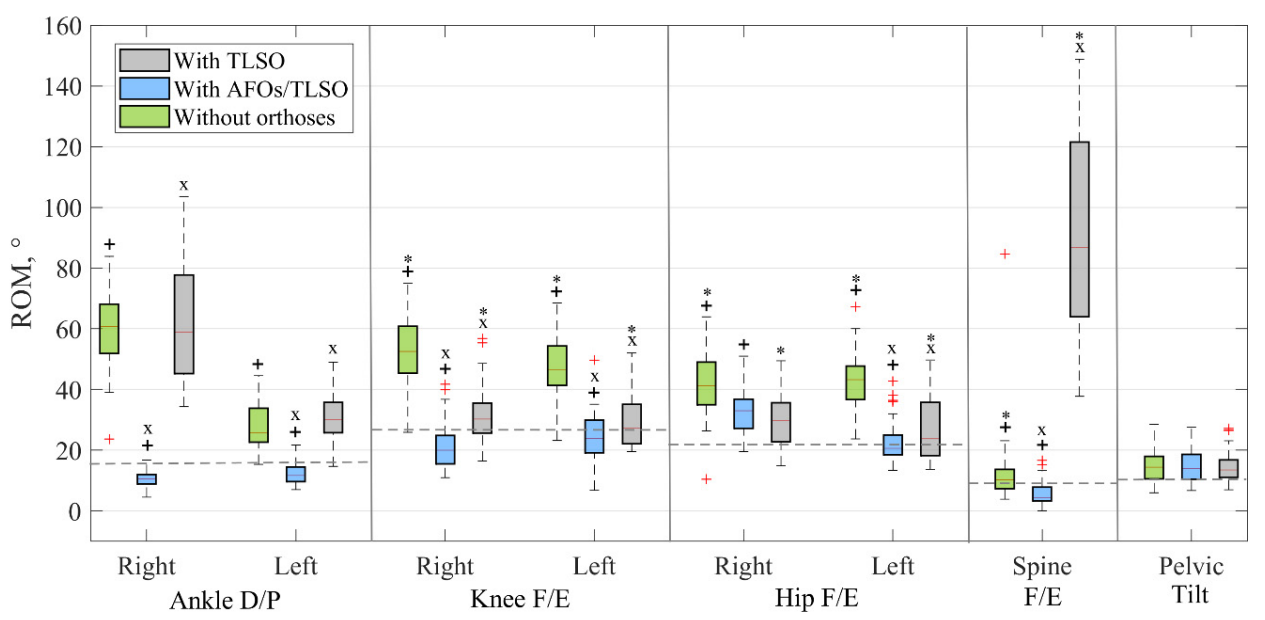

Fig. 5. ROMs in the sagittal plane: the dotted line indicates the norm limit according to the literature $[8,24]{ }^{*}{ }^{*}$ a significant difference $(p<0.05)$ between without orthoses and with TLSO orthosis. ${ }^{+}-$a significant difference $(p<0.05)$ between without orthoses and with AFOs/TLSO orthoses. ${ }^{x}-$ a significant difference $(p<0.05)$ between with TLSO orthosis and with AFOs/TLSO orthoses.

movement of body segments (Fig. 4) demonstrate that orthoses influence gait and amplitudes changes. However, each condition affects both gait parameters and body segment functionality differently. For example, ankle movements are severely restricted by wearing AFOs and TLSO, but the angle of the spine is reduced, which increases the stability of the spine while walking. And going with TLSO only, the spine demonstrated a pronounced high-amplitude spine motion and unusual shape knee angle curves, although the hip joint movements were closer to normal.

Analyzing the extremum values in Table 1 , statistically significant $(p<0.05)$ differences between conditions were obtained in the ankle, knee, and hip joints and in the spine. However, the effect was positive everywhere. Minimal $\Delta$ values, i.e. the highest efficiency, were observed: in ankle plantarflexion, knee extension, spine F/E and pelvic posterior tilt when walking with AFOs/TLSO; and in ankle dorsiflexion, and hip extension when walking with TLSO. The TLSO orthosis also provides better gait symmetry, i.e., there are statistically smaller differences between the sides of the body (Table 1).

ROMs in the sagittal plane (Fig. 5) revealed the closes values to the norm in ankle D/P with AFOs/TLSO and knee and hip F/E with TLSO. However, spine F/E demonstrated a very large ROM from the norm with TLSO. Statistically significant $(p<0.05)$ differences of ROMs between different conditions were obtained in the ankle, knee, and hip joints, and in the spine (Fig. 5).

The effectiveness of the measures was confirmed by the smaller $\Delta$ values in the double and single support, and stance time with AFOs/TLSO orthoses and in the double support and stance phase time with TLSO. Results of Table 2 revealed the main significant effect of measures in the stance and double support phases.

Statistically significant differences between body sides (Table 2) were found in the stance phase time when walking without orthoses and in step length with orthoses.

\section{Discussion}

This study aimed to determine the efficiency of AFOs and TLSO orthoses and their influence on gait of individual case-specific spastic diplegic $\mathrm{CP}$ subject. To achieve this goal, gait spatiotemporal and 
Table 2

Spatiotemporal parameters of gait under different conditions $(n=29)$

\begin{tabular}{|c|c|c|c|c|c|}
\hline Parameters & $\begin{array}{l}\text { Body } \\
\text { side }\end{array}$ & Norms & $\begin{array}{c}\text { Without orthoses } \\
n=10\end{array}$ & $\begin{array}{c}\text { With AFOs/TLSO orthoses } \\
n=7\end{array}$ & $\begin{array}{c}\text { With TLSO } \\
n=12\end{array}$ \\
\hline \multirow[t]{2}{*}{ Cadence, steps/min } & Right & $146.3^{[10]}$ & $79.8 \pm 13.4(71.2-83.2)$ & $61.7 \pm 32.4(55.0-83.3)^{x}$ & $83.2 \pm 9.9(78.2-91.3)^{x}$ \\
\hline & Left & & $84.9 \pm 10.1(79.1-88.9)$ & $80.4 \pm 14.1(68.2-93.0)$ & $80.3 \pm 7.2(75.7-87.3)$ \\
\hline \multirow[t]{2}{*}{$\Delta$, steps $/ \mathrm{min}$} & Left & - & -66.5 & -84.6 & -63.1 \\
\hline & Right & & -61.4 & -65.9 & -66.0 \\
\hline \multirow[t]{2}{*}{ Walking speed, $\mathrm{m} / \mathrm{s}$} & Right & $1.24^{[10,12]}$ & $0.38 \pm 0.13(0.29-0.47)$ & $0.42 \pm 0.38(0.25-0.31)$ & $0.31 \pm 0.14(0.21-0.41)$ \\
\hline & Left & & $0.47 \pm 0.07(0.40-0.54)$ & $0.25 \pm 0.04(0.24-0.29)^{x}$ & $0.36 \pm 0.11(0.31-0.43)^{x}$ \\
\hline \multirow[t]{2}{*}{$\Delta, \mathrm{m} / \mathrm{s}$} & Left & - & -0.86 & -0.82 & -0.93 \\
\hline & Right & & -0.77 & -0.99 & -0.88 \\
\hline \multirow[t]{2}{*}{ Stride time, $\mathrm{s}$} & Right & $0.83^{[10]}$ & $1.54 \pm 0.25(1.44-1.69)$ & $1.48 \pm 0.54(1.42-1.83)$ & $1.46 \pm 0.18(1.32-1.54)$ \\
\hline & Left & & $1.43 \pm 0.16(1.35-1.52)$ & $1.54 \pm 0.27(1.29-1.76)$ & $1.51 \pm 0.14(1.38-1.59)$ \\
\hline \multirow[t]{2}{*}{$\Delta, \mathrm{s}$} & Left & - & 0.71 & 0.65 & 0.63 \\
\hline & Right & & 0.60 & 0.71 & 0.68 \\
\hline \multirow[t]{2}{*}{ Step time, s } & Right & $0.42^{[10]}$ & $0.75 \pm 0.09(0.70-0.78)$ & $0.89 \pm 0.32(0.67-1.09)$ & $0.77 \pm 0.13(0.68-0.83)$ \\
\hline & Left & & $0.70 \pm 0.14(0.62-0.77)$ & $0.75 \pm 0.09(0.69-0.83)$ & $0.72 \pm 0.08(0.66-0.76)$ \\
\hline \multirow[t]{2}{*}{$\Delta, \mathrm{s}$} & Left & - & 0.33 & 0.47 & 0.35 \\
\hline & Right & & 0.28 & 0.33 & 0.30 \\
\hline \multirow[t]{2}{*}{ Stride length, $\mathrm{m}$} & Right & $1.05^{[10,12]}$ & $0.56 \pm 0.23(0.39-0.69)$ & $0.41 \pm 0.12(0.34-0.53)$ & $0.47 \pm 0.23(0.28-0.62)$ \\
\hline & Left & & $0.68 \pm 0.14(0.59-0.80)$ & $0.39 \pm 0.10(0.37-0.48)$ & $0.54 \pm 0.17(0.44-0.68)$ \\
\hline \multirow[t]{2}{*}{$\Delta, \mathrm{m}$} & Right & - & -0.49 & -0.64 & -0.58 \\
\hline & Left & & -0.37 & -0.66 & -0.51 \\
\hline \multirow[t]{2}{*}{ Step length, $\mathrm{m}$} & Right & $0.52^{[10]}$ & $0.30 \pm 0.06(0.27-0.34)^{+}$ & $0.12 \pm 0.09(0.05-0.21)^{x+}$ & $0.35 \pm 0.13(0.25-0.43)^{x}$ \\
\hline & Left & & $0.36 \pm 0.13(0.34-0.45)^{*}$ & $0.35 \pm 0.06(0.33-0.37)^{x}$ & $0.21 \pm 0.11(0.16-0.24)^{* x}$ \\
\hline \multirow[t]{2}{*}{$\Delta, \mathrm{m}$} & Right & - & -0.22 & -0.40 & -0.17 \\
\hline & Left & & -0.16 & -0.17 & -0.31 \\
\hline \multirow[t]{2}{*}{ Step width, $\mathrm{m}$} & Right & $0.116^{[12]}$ & $0.31 \pm 0.03(0.28-0.34)$ & $0.41 \pm 0.26(0.29-0.34)$ & $0.33 \pm 0.10(0.26-0.39)$ \\
\hline & Left & & $0.27 \pm 0.07(0.24-0.32)^{*+}$ & $0.42 \pm 0.33(0.27-0.29)^{+x}$ & $0.36 \pm 0.06(0.33-0.40)^{* x}$ \\
\hline \multirow[t]{2}{*}{$\Delta, \mathrm{m}$} & Right & - & 0.19 & 0.29 & 0.21 \\
\hline & Left & & 0.15 & 0.30 & 0.24 \\
\hline \multirow[t]{2}{*}{ Double support, $\%$} & Right & $11.8^{[10]}$ & $15.4 \pm 11.4(4.9-21.9)$ & $13.1 \pm 19.6(3.5-8.7)$ & $13.5 \pm 7.9(8.1-17.7)$ \\
\hline & Left & & $18.6 \pm 8.2(11.5-27.3)$ & $11.4 \pm 5.4(7.6-14.8)$ & $17.8 \pm 6.2(13.4-21.6)$ \\
\hline \multirow[t]{2}{*}{$\Delta, \%$} & Right & - & 3.6 & 1.3 & 1.7 \\
\hline & Left & & 6.8 & -0.4 & 6.0 \\
\hline \multirow[t]{2}{*}{ Single support, $\%$} & Right & $44.0^{[10]}$ & $38.3 \pm 9.62(30.9-44.6)$ & $44.5 \pm 12.0(37.7-48.3)^{x}$ & $33.9 \pm 8.36(28.1-40.7)^{x}$ \\
\hline & Left & & $33.1 \pm 7.26(26.6-37.3)$ & $39.1 \pm 9.78(31.4-40.3)$ & $34.2 \pm 5.63(30.2-39.9)$ \\
\hline \multirow[t]{2}{*}{$\Delta, \%$} & Right & - & -5.7 & 0.5 & -10.1 \\
\hline & Left & & -10.9 & -4.9 & -9.8 \\
\hline \multirow[t]{2}{*}{ Stance, $\%$} & Right & $55.8^{[10]}$ & $71.1 \pm 7.4(65.9-77.3)^{*}$ & $69.7 \pm 27.7(44.9-77.4)$ & $64.3 \pm 7.4(62.9-68.2)^{*}$ \\
\hline & Left & & $62.4 \pm 6.8(57.9-65.5)$ & $59.2 \pm 9.1(55.3-60.8)$ & $63.7 \pm 4.9(60.5-68.0)$ \\
\hline \multirow{2}{*}{$\Delta, \%$} & Right & - & 15.3 & 13.9 & 8.5 \\
\hline & Left & & 6.6 & 3.4 & 7.9 \\
\hline
\end{tabular}

Data presented as mean $\pm \mathrm{SD}$ and IQR. ${ }^{*}$ - a significant difference $(p<0.05)$ between without orthoses and with TLSO orthosis. ${ }^{+}-$a significant difference $(p<0.05)$ between without orthoses and with AFOs/TLSO orthoses. ${ }^{x}-$ a significant difference $(p<0.05)$ between with TLSO orthosis and with AFOs/TLSO orthoses. Bold indicates a significant difference $(p<0.05)$ between right vs left. Norms have been taken from available scientific papers and sources are cited for each.

kinematics data were evaluated under three conditions in the sagittal plane and compared with normal gait parameters found in the literature $[8,10,12,24,28]$. Although many studies in the literature investigate the influence of AFOs and TLSO orthoses separately on CP gait [15,20-22], however, we have not found any studies investigating the efficacy of both orthoses together or combination of orthoses. Therefore, we believe that our study is new and might provide valuable information for both biomechanics and clinical practitioners. 
It is necessary to start from the fact that the gait of the subject is severely damaged and meets all the characteristic parameters of $\mathrm{CP}[1,5,9]$. This is confirmed by our results in barefoot. It is therefore quite clear that additional measures are inevitably needed to stabilize gait. It is also clear that measures are needed not only for the lower extremities but also for the spine, because without orthoses the child walks sharply reclining, i.e., spine position in extension is from $-66.7^{\circ}$ to $-79.0^{\circ}$. This change in the center of mass due to the position of the spine also results in larger-than-normal [8] pelvic motion amplitudes. Like other researchers $[25,26]$, we can confirm the fact that the position of the spine also affects the biomechanics of the lower extremities. We noticed, increased ROMs: in ankle ranged 26-60 ${ }^{\circ}$, while norm is $17.4^{\circ}$, in knee were $46-53^{\circ}$ (norm $26.7^{\circ}$ ), in hip $41-43^{\circ}$ (norm $21.5^{\circ}$ ). Secondly, irregular position of the joints during heel contact was detected: left ankle plantarflexion $10^{\circ}$, right knee flexion $9^{\circ}$, right hip flexion $60^{\circ}$ and pelvic posterior tilt $33^{\circ}$.

We found that both measures have an effect on gait parameters, but that effect is different for each body segment. The effectiveness of TLSO was manifested in: increased ankle dorsiflexion from 30.7 to $40.2^{\circ}$ in the right leg and from 7.7 to $25.5^{\circ}$ in the left leg (norm $37.03^{\circ}$ ); decreased hip extension from 31.7 to $-11.4^{\circ}$ on the right and from 6.7 to $-12.7^{\circ}$ on the left (norm $-9.93^{\circ}$ ); shortened and more close to normal double support and stance phases; and greater symmetry between movements. The results confirm the fact that the spine position influences gait parameters [25,26]. However, co-application of AFOs results in greater efficiency. First, placing AFOs on both legs in combination with TLSO provides good spinal stabilization, i.e. spine flexion decreases from $-66.7^{\circ}$ to $-7.8^{\circ}$ (norm $2.3^{\circ}$ ) and spine extension from -79.0 to $-13.3^{\circ}$ (norm $0.7^{\circ}$ ). Second, the highest efficiencies were observed in ankle plantarflexion (from $-29.4^{\circ}$ and $-20.7^{\circ}$ to 1.8 and 3.1 respectively at norm $-8.07^{\circ}$ ), knee extension (from $12.9^{\circ}$ and $-9.2^{\circ}$ to $-3.9^{\circ}$ and $-4.9^{\circ}$ kai norm NA) and pelvic posterior tilt movements from $39.0^{\circ}$ to $8.9^{\circ}$ (norm NA). In addition, the duration of the double support and stance phases is shortened and the duration of the single support phases is extended. This means longer standing time on one, which again means greater balance stability.

It is very important to mention that the child had been wearing the TLSO for a long time and was already used it, which we cannot say about AFOs, as the child only wore them for a week. Other researchers have also observed that the period of adaptation and the wear time of orthoses are important factors [29,30]. Therefore, we assume that prolonged wear of AFO's would further improve efficiency. Therefore, it is necessary to monitor changes in gait parameters after prolonged wear of AFOs, or to try to use orthoses of a different design, such as hinged AFOs, which allow to adjust the amplitude of ankle movements [16,20]. However, not only quantitative parameters should be taken into account, but also the child's willingness to wear appropriate equipment and comfort.

Unfortunately, we also see the limitations of our work. We analyzed gait only in the sagittal plane, so the values occurring in other planes that would explain the compensatory mechanisms of movements characteristic of pathological gait were not evaluated. In addition, the results may have been affected by the short wear time of the AFOs before the start of the study.

\section{Conclusions}

Our results revealed that different measures have different effects on the lower limb and back segments. The best stability of the spine, ankle plantarflexion, and knee hyperextension is achieved by using TLSO and AFOs together, therefore, in this case, we can consider this combination to be the most effective. Differences between the sides of the body due to scoliosis are best eliminated by wearing only a TLSO orthosis. Obviously, at least one of these means must be worn by the child, taking into account the comfort of the child, i.e., without restricting his movements by an excessive number of means. 


\section{Acknowledgments}

The authors would like to thank the medical team of the Children's Hospital in Vilnius University Hospital Santaros clinics who participated in the collection of research data.

\section{Conflict of interest}

None to report.

\section{References}

[1] Rodda JM, Graham HK, Carson L, et al. Sagittal gait patterns in spastic diplegia. J Bone Jt Surg - Ser B 2004; 86: 251-258.

[2] Winters TF, Gage JR, Hicks R. Gait patterns in spastic hemiplegia in children and young adults. J Bone Jt Surg - Ser A 1987; 69: 437-441.

[3] Szopa A, Domagalska-Szopa M, Czamara A. Gait pattern differences in children with unilateral cerebral palsy. Res Dev Disabil 2014; 35: 2261-6.

[4] Elnaggar RK. Relationship between transverse-plane kinematic deviations of lower limbs and gait performance in children with unilateral cerebral palsy: A descriptive analysis. Gait Posture 2020; 79: 224-228.

[5] Armand S, Decoulon G, Bonnefoy-Mazure A. Gait analysis in children with cerebral palsy. EFORT Open Rev 2016; 1: 448-460.

[6] Park EY. Path analysis of strength, spasticity, gross motor function, and health-related quality of life in children with spastic cerebral palsy. Health Qual Life Outcomes 2018; 16: 70.

[7] Patel DR, Neelakantan M, Pandher K, et al. Cerebral palsy in children: A clinical overview. Transl Pediatr 2020; 9: S125-S135.

[8] Zakaria NK, Jailani R, Tahir N. Gender differences in gait features of healthy children. J Teknol 2015; 77: 1-6.

[9] Domagalska-Szopa M, Szopa A. Gait pattern differences among children with bilateral cerebral palsy. Front Neurol; 10. Epub ahead of print 2019. doi: 10.3389/fneur.2019.00183.

[10] Lythgo N, Wilson C, Galea M. Basic gait and symmetry measures for primary school-aged children and young adults whilst walking barefoot and with shoes. Gait Posture 2009; 30: 502-506.

[11] Leban B, Cimolin V, Porta M, et al. Age-related changes in smoothness of gait of healthy children and early adolescents. https://doi.org/101080/0022289520191680949 2019; 52: 694-702.

[12] Hallemans A, Verbecque E, Dumas R, et al. Developmental changes in spatial margin of stability in typically developing children relate to the mechanics of gait. Gait Posture 2018; 63: 33-38.

[13] Kim CJ, Son SM. Comparison of Spatiotemporal Gait Parameters between Children with NormalDevelopment and Children with Diplegic Cerebral Palsy. J Phys Ther Sci 2014; 26: 1317.

[14] Dini P, David A. Repeatability of spatiotemporal gait parameters: Comparison between normal children and children with hemiplegic spastic cerebral palsy. Brazilian J Phys Ther 2009; 13: 215-222.

[15] Ries AJ, Novacheck TF, Schwartz MH. The efficacy of ankle-foot orthoses on improving the gait of children with diplegic cerebral palsy: A multiple outcome analysis. $P M \& R$ 2015; 7: 922-929.

[16] Radtka SA, Skinner SR, Johanson ME. A comparison of gait with solid and hinged ankle-foot orthoses in children with spastic diplegic cerebral palsy. Gait Posture 2005; 21: 303-310.

[17] Aboutorabi A, Arazpour M, Ahmadi Bani M, et al. Efficacy of ankle foot orthoses types on walking in children with cerebral palsy: A systematic review. Ann Phys Rehabil Med 2017; 60: 393-402.

[18] Son I, Lee D, Hong S, et al. Comparison of gait ability of a child with cerebral palsy according to the difference of dorsiflexion angle of hinged ankle-foot orthosis: A case report. Am J Case Rep 2019; 20: 1454.

[19] Buckon CE, Thomas SS, Jakobson-Huston S, et al. Comparison of three ankle-foot orthosis configurations for children with spastic diplegia. Dev Med Child Neurol 2004; 46: 590-598.

[20] Kane KJ, Musselman KE, Lanovaz J. Effects of solid ankle-foot orthoses with individualized ankle angles on gait for children with cerebral palsy and equinus. J Pediatr Rehabil Med 2020; 13: 169-183.

[21] Contini BG, Bergamini E, Alvini M, et al. A wearable gait analysis protocol to support the choice of the appropriate ankle-foot orthosis: A comparative assessment in children with Cerebral Palsy. Clin Biomech 2019; 70: 177-185.

[22] Elnaggar RK, Abd-Elmonem AM. Effects of radial shockwave therapy and orthotics applied with physical training on motor function of children with spastic diplegia: A randomized trial. Phys Occup Ther Pediatr 2019; 39: 692-707. 
[23] Song S, Lee K, Jung S, et al. Effect of horizontal whole-body vibration training on trunk and lower-extremity muscle tone and activation, balance, and gait in a child with cerebral palsy. Am J Case Rep 2018; 19: 1292.

[24] Abbasi L, Rojhani-Shirazi Z, Razeghi M, et al. Trunk kinematic analysis during gait in cerebral palsy children with crouch gait pattern. J Biomed Phys Eng 2018; 8: 281.

[25] Domagalska-Szopa M, Szopa A. Gait pattern differences between children with mild scoliosis and children with unilateral cerebral palsy. PLoS One 2014; 9: e103095.

[26] Szopa A, Domagalska-Szopa M, Siwiec A, et al. Canonical correlation between body-posture deviations and gait disorders in children with cerebral palsy. PLoS One 2020; 15: e0234654.

[27] Lilliefors HW. On the kolmogorov-smirnov test for normality with mean and variance unknown. J Am Stat Assoc 1967; 62: 399-402.

[28] Kuwahara W, Deie M, Fujita N, et al. Characteristics of thoracic and lumbar movements during gait in lumbar spinal stenosis patients before and after decompression surgery. Clin Biomech 2016; 40: 45-51.

[29] Delafontaine A, Fourcade P, Honeine JL, et al. Postural adaptations to unilateral knee joint hypomobility induced by orthosis wear during gait initiation. Sci Reports. 2018; 830: 1-15.

[30] Schwarze M, Horoba L, Block J, et al. Wearing time of ankle-foot orthoses with modular shank supply in cerebral palsy: A descriptive analysis in a clinically prospective approach. Rehabil Res Pract 2019; 2019: 9. 